\title{
A propos d'une amphore du Peintre d'Amasis conservée au Cabinet des Médailles de la Bibliothèque Nationale de France à Paris : trois grandes divinités de l'Athènes archaïque.
}

\author{
Marie-Christine Villanueva Puig[i]
}

\begin{abstract}
Résumé
Le programme iconographique d'une amphore attique à figures noires, datée vers 540, signée du potier Amasis et attribuée au Peintre d'Amasis (Cabinet des Médailles de la Bibliothèque Nationale de France à Paris), est réexaminé. A partir de celui-ci, on se propose d'évaluer l'importance documentaire des images portées par les vases dans l'approche de l'histoire socio-religieuse de l'Athènes archaïque. Mots-clés: Athènes archaïque; vie cultuelle; organisation du Céramique; artisan.
\end{abstract}

A respeito de uma ânfora do Pintor de Amásis conservada no Cabinet des Médailles da Biblioteca Nacional da França, em Paris: três grandes divindades da Atenas arcaica

\section{Resumo}

O programa iconográfico de uma ânfora ática de figuras negras, datada de cerca de 540 a. C., assinada pelo oleiro Amasis e atribuído ao Pintor de Amasis (Cabinet des Médailles da Biblioteca Nacional da França, em Paris) é reexaminado. A partir disso, propõe-se avaliar a importância documental das imagens veiculadas pelos vasos numa abordagem de história sócio-religiosa da Atenas arcaica.

Palavras-chave: Atenas arcaica; vida cultual; organização do Cerâmico; artesão.

About an Amasis Painter's amphora kept in the Cabinet des Médailles of France's National Library in Paris: three Archaic Athens'great deities.

\begin{abstract}
The iconographic ensemble of an Attic black-figured amphora dated c. 540, signed by Amasis the potter and attributed to the Amasis Painter (Cabinet des Médailles de la Bibliothèque Nationale de France in Paris) is re-examined. The goal of this paper is to give the opportunity of evaluating the importance of the iconographic programme used in the production of vases as a way of understanding the archaic City's social and religious life.
\end{abstract}

Keywords: Archaic Athens; cultual life; Athenian Kerameikos; craftman.

Con respecto de una ánfora del Pintor de Amasis conservada en el Cabinet des Médailles de la Biblioteca Nacional de Francia en Paris: tres grandes divinidades de Atenas Arcaica.

\section{Resumen}

El programa iconográfico de una ánfora ática de figuras negras, de más o menos 540 a. C., firmada por el alfarero Amasis y atribuído al Pintor de Amasis (Cabinet des Médailles da Biblioteca Nacional de Francia en Paris) es examinado más una vez. A partir de este hecho, se propone evaluar la importancia de ese documento de las imágenes transmitidas por los jarrones en un enfoque de la história sócio-religiosa de Atenas arcaica.

Palabras-clave: flor; charis; philia. 
ne exposition Du Rouge et du Noir. Les vases grecs de la collection de Luynes $^{2}$ réunit au Cabinet des Médailles de la Bibliothèque Nationale de France (2014-215) la prestigieuse collection de vases grecs rassemblée par le Duc de Luynes dont il a fait don à cette institution en 1862, avec un ensemble très important d'antiques variés : bronzes, monnaies, vases, bijoux, camées ... Ces oeuvres y sont toujours conservées. L'événement fournit l'occasion de réexaminer l'une des pièces de cette très riche donation, exceptionnelle à plusieurs titres. Il s'agit d'une amphore à col, attique à figures noires $^{3}$ (fig. 1ab), dont la date de fabrication se situe dans le troisième quart du VI siècle avant notre ère, vers 540. Elle provient des fouilles de la nécropole étrusque de Vulci, et a fait partie de la collection Durand avant d'appartenir au Duc de Luynes.

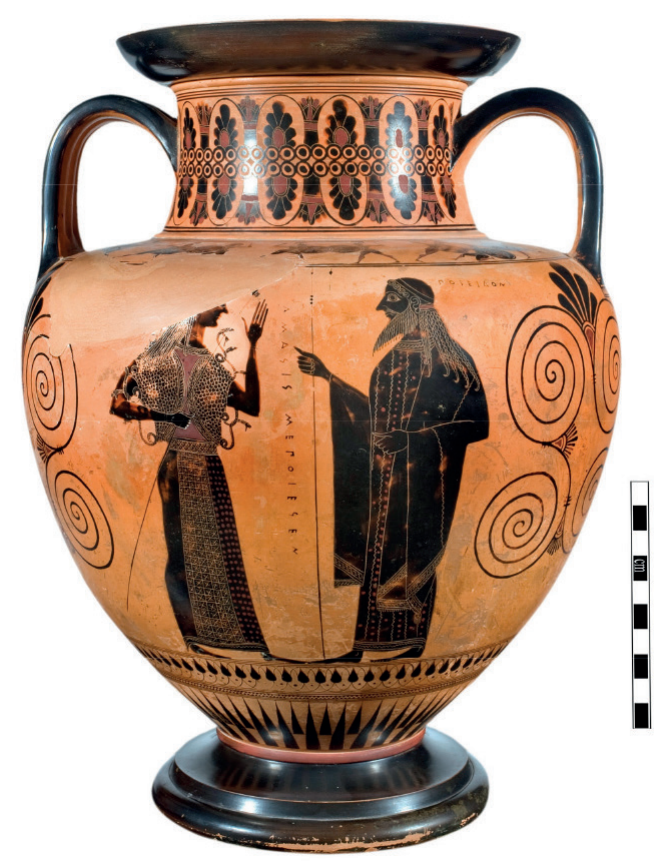

Figura $1 \mathrm{~A}$ 


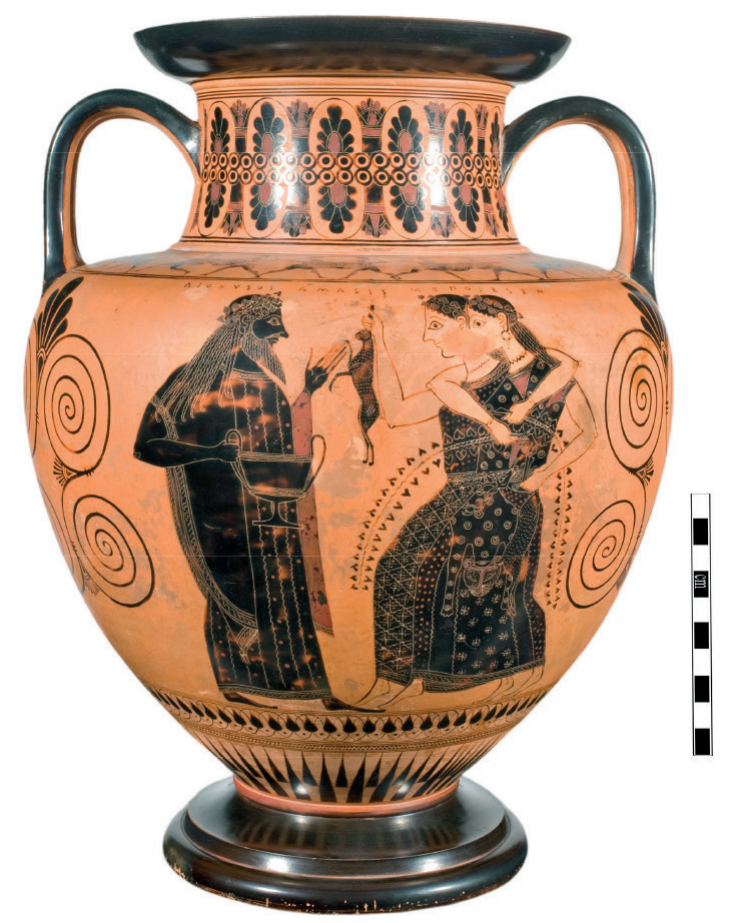

Figura 1 B

Sa forme élaborée, les qualités graphiques de son décor figuré, son riche système ornemental et son exceptionnel programme iconographique, les inscriptions enfin qu'elle porte, dont une signature, tout invite à la reconsidérer. A partir de cette œuvre, je voudrais poser, à nouveau, la question des données que peut procurer à l'historien des sociétés anciennes, les images portées par les vases peints. Elle est naturellement liée à celle de leur contexte de production, à celle du choix des représentations opéré par la Cité à un moment précis de son histoire et de l'image qu'elle souhaite donner d'elle. Est-elle aussi marquée, orientée par le peintre lui-même? son commanditaire? selon des groupes sociaux bien difficiles à appréhender dans le monde de l'Athènes archaïque. L'exceptionnelle qualité jointe à une profonde originalité de cette œuvre attribuée au Peintre d'Amasis invite à examiner le point.

La forme particulière de l'amphore, plutôt trapue avec des anses trifides jointe à une riche décoration secondaire l'a fait rapprocher de la Botkin Class ${ }^{4}$, une petite série de vases définie par Beazley ${ }^{5}$ et traditionnellement considérée comme fortement marquée par une influence orientale ${ }^{6}$. Cependant, $\mathrm{H}$. Mommsen, dans une étude récente ${ }^{7}$, revient sur ce point, pour, au contraire,

\footnotetext{
${ }^{4}$ Von Bothmer (1985, p. 127-128 et 132) qui envisage même que ces amphores aient été tournées par le potier Amasis au début de sa carrière; voir à ce propos la mise au point de Mommsen (1997, p. 17-34).

${ }^{5}$ Beazley (1931, p. 284) : il s'agit d'un petit groupe (qui comporte désormais neuf pièces) qui doit son nom au vase éponyme de l'Ermitage de Saint-Pétersbourg B. 4464 (ABV 159-160, 4) ayant appartenu au peintre Michail Pavlovitch Botkin.

${ }^{6}$ Voir en particulier Jackson (1976, p. 29-37 et spécialement p. 34-35 et fig. 17) pour notre vase; Mommsen (1997, p. 17-34).

${ }^{7}$ Mommsen (2009, p. 31-46).
} 
intégrer cette série dans la production attique du moment, dont le potier Amasis se serait inspiré, tout spécialement pour notre amphore. De ce décor, il faut noter en particulier la double frise de palmettes et de boutons de lotus sur le col, le motif complexe de larges spirales et de palmettes avec un grand bouton de lotus suspendu sous les anses à l'attache marquée par des triangles suspendus, enfin le bas de la panse décorée d'arêtes rayonnantes surmontées d'une frise de boutons de lotus. Un parfum d'exotisme, néanmoins remis en cause, à suivre dans les autres aspects du vase.

Le vase présente trois scènes figurées: une de chaque côté de la panse et une sur l'épaule. Sur chaque face du vase, on peut lire des inscriptions : une signature AMASIS MEPOIESEN, “Amasis m'a fait”, la signature du potier qui apparaît deux fois. Sur la face A, elle se lit verticalement, tracée entre les deux figures représentées face à face. Sur la face $\mathrm{B}$, elle réapparait, horizontalement cette fois, située au-dessus des têtes des trois figures. De plus, les noms des personnages représentés sont inscrits: sur la face $\mathrm{A}$, au-dessus de la tête du personnage barbu, à droite, on peut lire POSEIDON; sur la face B, au-dessus du personnage masculin, DIONYSOS.

L' épaule du vase est décorée d'une frise miniaturiste, très animée : on y voit une série de duels d'hoplites entre lesquels s'intercale un groupe plus complexe de trois guerriers dont l'un, blessé par son adversaire, est déjà au sol, tandis qu'un troisième combattant s'approche pour lui venir en aide. Tous portent le même équipement : casque de type corinthien à haut cimier, cuirasse, cnémides, bouclier rond et lance. Sous les anses, un homme sonne l'alarme en soufflant dans une corne et un archer, à la coiffe orientale pointue, fuit en se retournant.

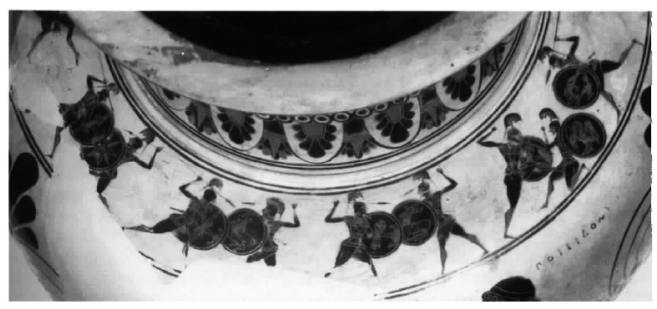

Figura $2 \mathrm{~A}$

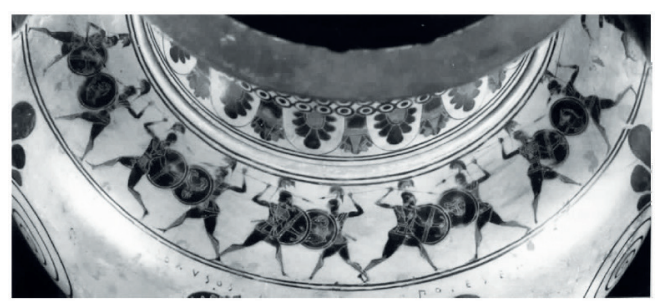

Figura 2 B

Les deux scènes qui décorent la panse de l'amphore sont en contraste avec l'agitation violente de la scène de combat de l'épaule. Sur la face A, sont représentées, debout, immobiles et face à face, une figure féminine et une figure 
masculine, séparées par la signature verticale d'Amasis déjà signalée. A gauche, se trouvait sans doute une autre inscription, aujourd'hui disparue, comme celle qu'on peut lire encore près du personnage de droite. La déesse Athéna est néanmoins aisément reconnaissable. Elle est vêtue d'un péplos richement brodé. Sur ses épaules, elle porte l'égide, la peau de chèvre rendue par des écailles et bordée de serpents qui se détachent nettement sur l'argile du vase. Il s'agit d'un cadeau de Zeus son père qui la rend invulnérable. Elle portait un casque sur sa longue chevelure, dont n'est conservé que le protège-nuque. De sa main droite, elle tient une lance. La déesse avance vers le personnage qui lui fait face, en levant la main gauche, dans un geste de salutation. Face à elle, se tient Poséidon, identifié par une inscription, comme cela a été vu, et aussi reconnaissable au trident qu'il tient dans sa main gauche et qui le désigne comme souverain des mers. Il est habillé d'un long chiton plissé et d'un himation. Sa chevelure tressée est retenue par un bandeau.

Sur la face B de la panse, à gauche, se trouve Dionysos, dont le nom est inscrit au-dessus de la tête. Il est représenté comme un dieu d'âge mûr, conformément à l'usage durant l'époque archaïque: il est barbu et porte les cheveux longs, comme Poséidon sur l'autre face. Sa chevelure, cependant, n'est pas tressée mais couronnée de lierre. Il tient de sa main droite un grand canthare, un vase à boire aux anses hautes. Le lierre au feuillage toujours vert et le vase à vin sont en effet deux de ses attributs caractéristiques et habituels. Sa main gauche est levée en direction de deux ménades ${ }^{8}$ qui se dirigent vers lui d'un pas vif et dansant. En outre, chacune passe le bras sur l'épaule de l'autre. Toutes deux sont couronnées de lierre comme le dieu et chacune tient un rameau de lierre à la main. Elles sont vêtues d'un péplos richement brodé et ceinturé et portent des bijoux : boucles d'oreilles, colliers et bracelets. La plus éloignée du spectateur tend à Dionysos un lièvre qu'elle tient par les oreilles. La plus proche porte une peau de panthère (pardalide) nouée sur son péplos : on peut distinguer la tête et les pattes de l'animal. De la main gauche, elle tient un faon. Ainsi, sur cette figure, on peut noter trois motifs différents superposés: la broderie du péplos, la peau ocellée de la panthère, et celle, tachetée, du faon, un rendu virtuose dans l'utilisation de l'incision, caractéristique de la technique à figures noires. Les ménades sont ici représentées comme des chasseresses qui apportent les produits de leur chasse en hommage à leur dieu.

Diverses sources écrites permettent de dresser un tableau historique dans lequel Athéna, Poséidon et Dionysos représentés sur l'amphore constituent trois grandes divinités dans l'Athènes archaïque. Le vase a été créé durant la période où le tyran Pisistrate gouverne la Cité (il prend le pouvoir pour la première fois en 560, puis gouverne Athènes sans interruption de 546-545 à sa mort en 528527 , ses fils lui succèdent alors jusqu'en 511-510). Or, on lui attribue un rôle

${ }^{8}$ La désignation de ces figures féminines autour de Dionysos est loin de faire l'unanimité est loin de faire l'unanimité. Je me suis expliquée sur mon choix de les appeler "ménades" dans Ménades (2009, p. 22-23); depuis, voir, sur les occurrences littéraires de ces termes, Bonansea (2008, p. 107-130), et un bon état de la question par Lindblom (2011, p. 135-146); autre point de vue chez Isler-Kerényi (2015, p. 4-8). 
important dans l'orientation de son développement religieux ${ }^{9}$ dont une transformation importante de la grande fête des Panathénées qui célèbre Athéna, la divinité poliade, un enrichissement notable du programme de ses manifestations. Le tyran se présentait d'ailleurs lui-même comme choisi par la déesse pour gouverner sa cité: c'est ce que nous révèle l'anecdote de l'étrange mise en scène d'un de ses retours à Athènes rapportée par Hérodote, selon laquelle il monte en char à l'Acropole, accompagné d'une grande et belle jeune femme qu'il fait passer pour Athéna elle-même ${ }^{10}$. Quant à Poséidon, son importance dans l'histoire d'Athènes est moins aisée à dégager avec précision. En effet, dans le mythe de fondation de la Cité, au temps où les dieux rivalisent pour régner sur les différentes cités grecques en divinités poliades, et s'en répartir les hommages, Poséidon est vaincu par Athéna et la cité se nomme Athènes ${ }^{11}$. A l'époque classique, sources littéraires et figurées, tout particulièrement le fronton Ouest du Parthénon conçu par Phidias, attestent le conflit, j'y reviendrai. Mais que connaissons-nous de la place de Poséidon dans l'Athènes archaïque ? Pisistrate aurait eu un attachement particulier pour ce dieu, lié à sa revendication de lien de parenté avec le héros homérique Nélée de Pylos, fils de Poséidon. Nélée est le père de Nestor dont le fils, qui s'appelle précisément Pisistrate, accueille Télémaque en quête de nouvelles de son père Ulysse au chant III de l'Odyssée ${ }^{12}$. Or, dans l'Athènes du VIe siècle, les poèmes homériques sont bien connus et il est difficile d'envisager le nom de Pisistrate sans référence à Homère ${ }^{13}$. Sans doute, Pisistrate a t-il favorisé d'une manière ou d'une autre le culte du dieu patron de ses ancêtres héroïques ${ }^{14}$. Le culte de Dionysos enfin, connaît, dans l'Athènes des Pisistratides un développement particulier que l'on propose d'attribuer à un choix délibéré du tyran ${ }^{15}$. Il aurait introduit le culte de Dionysos Eleuthereus et institué les Grandes Dionysies qui comportent, à partir de 536, des concours tragiques ${ }^{16}$. Ce serait en tant que divinité régulatrice, emblématique de l'unité et de la pacification recherchées par le tyran, que le culte de Dionysos aurait les faveurs de celui- $\mathrm{ci}^{17}$. En ce qui concerne les vases peints, l'imagerie dionysiaque est extrêmement présente, et il faut se souvenir, pour évaluer au plus juste cette donnée que, de manière générale, de très nombreux vases servent à la consommation du vin dans le contexte du symposion, un des

\footnotetext{
'L'ouvrage de Shapiro (1989) et le supplément (1995), constituent une enquête spécialement riche et documentée sur ce thème; voir aussi Angiolillo (1997).

${ }^{10}$ Hérodote 1,60 .

"Voir le récit de l'épisode dans Apollodore. Bibliothèque III, 14; à propos de cet affrontement aux origines de la cité d’Athènes, voir en particulier l'analyse de Loraux (1981, p. 204-205). Parke (1987, p. 187-214).

${ }^{12}$ Odyssée III 36.

${ }^{13}$ Hérodote V, 65 mentionne le lien entre le nom du tyran et celui du fils de Nestor.

${ }^{14}$ Voir Shapiro (1989, p. 103-104).

${ }^{15}$ Shapiro (1989, p. 85-87) et Isler-Kérényi (2007, p. 218-223) pour des visions nuancées des liens entre le tyran et le culte dionysiaque et un essai de mise au point de sa stratégie en ce domaine.

${ }^{16}$ Parker (1996, p. 92 et suiv.) cependant est sceptique sur l'attribution de ces innovations au règne des Pisistratides.

${ }^{17}$ Angiolillo (1997, p. 142) et Isler-Kérényi (2015, p. 220); Stähli (1999, p. 195-196), met l’accent sur le changement de fonction du dieu dans l'Athènes d'alors, la réorganisation de ses fêtes correspond à une plus forte intégration de son culte dans la cité: Dionysos devient un dieu urbain.
} 
domaines dont le dieu est maître ${ }^{18}$. On a aussi noté, cette fois comme caractéristique de ce moment particulier, la présence forte d'éléments cultuels dans cette imagerie, intérêt sans doute à lier à des innovations dans ce domaine ${ }^{19}$.

Ainsi, des sources d'un autre type permettent de corroborer l'importance des trois divinités représentées sur l'amphore, dans l'Athènes de son temps. Une fois établi ce cadre historique général de la création de l'image à l'aide de documents d'un autre type, aller plus avant implique d'insérer le vase dans une double série de représentations : l'image des divinités chez notre peintre estelle semblable ou différente de leurs figurations par d'autres peintres ? Si c'est le cas, alors c'est le corpus du peintre lui-même qu'il faut interroger, en y replaçant les scènes de notre vase afin d'appréhender au mieux son originalité, sa marge de liberté dans le choix et le traitement de ses thèmes.

\section{Le tyran se présentait d'ailleurs lui-même comme choisi par la déesse pour gouverner sa cité}

Regardons de plus près le programme iconographique de l'amphore de Paris, dans la perspective d'y repérer les traits appartenant à la tradition et ceux, au contraire qui représentent une nouveauté. Sur la face A du vase, la rencontre d'Athéna et de Poséidon est paisible alors que la tradition la plus commune est celle de leur lutte pour la possession de l'Attique. La source écrite la plus ancienne sur ce conflit est Hérodote qui compose L'Enquête environ un siècle après notre vase ${ }^{20}$. Plutarque, qui écrit au $1^{\mathrm{er}}$ siècle de notre ère, évoque dans $l a$ vie de Thémistocle cette lutte et la victoire d'Athéna lorsqu'il fait état de l'aménagement du port du Pirée par Thémistocle. Celui-ci voulait lier sa Cité à la mer et comme l'y attacher, menant ainsi une politique contraire à celle des anciens rois d'Athènes qui souhaitaient détourner les citoyens de la navigation mais les voir cultiver la terre. C'est dans ce but, au dire de Plutarque, qu'ils auraient répandu l'histoire de la rivalité entre les deux divinités et la victoire de l'olivier d'Athéna sur la mer de Poséidon. La représentation la plus célèbre de cette dispute est celle qu'a conçue Phidias pour le fronton Ouest du Parthénon, exécutée dans les années 438-432. Sa situation sur l'Acropole, lieu même du déroulement de l'épisode et sa place sur l'édifice même, en résonnance avec la scène de la naissance de la déesse qui occupe à l'Est le fronton principal rehaussent la valeur de son image en tant qu'épisode lié au fondement même de la Cité et du nom qu'elle porte. Bien peu de choses restent de cette œuvre mais un dessin réalisé en 1674, avant l'explosion qui a gravement endommagé le bâtiment en

${ }^{18}$ Sur ce point, voir notamment Shapiro (1989, p. 84 et 100).

${ }^{19}$ Voir l'analyse subtile de Stähli (1999, p. 195-196), sur la fonction de l'image ménadique, et ses rapports avec l'univers cultuel: l'affirmation de cette iconographie sur les vases correspond à une demande accrue de la clientèle du moment et à sa diversification, sans que l'on puisse voir dans la mise en place ou la modification des cultes l'origine, proprement dite du type iconographique de la ménade; voir aussi Isler-Kerényi (2015, p. 221-222).

20Hérodote, Histoire, VIII, 155. 
1687 permet d'en restituer la composition d'ensemble ${ }^{21}$. Au centre du fronton, les deux divinités s'affrontent dans un mouvement de lutte, violent et divergent, rendu par une composition en $\mathrm{V}$ dans laquelle les corps des deux adversaires sont tendus et rejetés en arrière. Le groupe central est entouré par les chevaux des quadriges des deux adversaires, qui se cabrent. Dans les angles, se trouvent probablement Kékrops, roi d'origine, mi-homme mi-serpent, déjà humain mais encore lié aux créatures monstrueuses issues de la terre, et sa fille Pandrosos que la présence d'un serpent aide à identifier ${ }^{22}$. La célébrité de l'œuvre trouve un écho dans des compositions de peintres de vases d'époque postérieure. Par exemple, une hydrie attique à figures rouges datée vers 400 et provenant de Pella ${ }^{23}$, semble inspirée de la vigoureuse composition tympanale : au centre, le grand foudre de Zeus sépare les adversaires. A gauche, Athéna est partiellement conservée. A ses pieds, on distingue, l'olivier, une Niké, signe de sa victoire dans le conflit, et Kékrops, mi-homme mi-serpent qui ancre la scène à Athènes, à la fois, dans le sol de la Cité et dans son passé lointain. A droite, Poséidon est figuré en hoplite. Il recule vivement et derrière lui, Amphitrite, son épouse, maintient son cheval blanc et cabré. A ses pieds, sont représentés un dauphin et un monstre marin.

Sur la face A du vase, la rencontre d'Athéna
et de Poséidon est paisible alors que la tradition
la plus commune est celle de leur lutte pour
la possession de l'Attique

Cependant, Poséidon le perdant, reste bien présent à Athènes et même sur l'Acropole où les traces de son occupation remontent au plus lointain passé d'Athènes. En effet, il est un des dieux et héros auxquels un culte est rendu dans l'Erechthéion, édifice complexe élevé au Nord de l'Acropole à la fin du Ve siècle: il y partage un autel avec Erechthée. Au second siècle de notre ère, le voyageur Pausanias y voit encore l'empreinte du trident du dieu sur le rocher et un puits où l'on entend le bruit des vagues de la mer, vestiges de la lutte de Poséidon pour revendiquer ses droits sur l'Attique ${ }^{24}$.

\footnotetext{
${ }^{21}$ Rolley (1999, p. 71, fig. 59 et p. 76-78) ; le dessin, réalisé pour le Marquis de Nointel, ambassadeur de France à Constantinople, est traditionnellement attribué à J. Carrey, dessinateur officiel du Marquis mais qui n'était probablement pas avec lui à Athènes ; les fragments conservés se trouvent partagés entre le British Museum à Londres et le Musée du Louvre à Paris.

${ }^{22} \mathrm{~A}$ propos de Kékrops, voir en particulier Gourmelen (2004).

${ }^{23}$ Musée de Pella Ma 80.514: BA 17333. Hesperia 82, 2013, p. 597-602, fig. 1-8; voir aussi une hydrie à figures en relief, en provenance de Kertch, en Crimée, conservée au Musée de l'Ermitage de Saint-Pétersbourg KAB6A, datée du second quart du IV siècle (BA 6988; Antike Kunst 54, 2011 pl. 6, 1-2): Poséidon retient son cheval, à ses pieds il y a deux dauphins (allusion à la mer salée) et, en face de lui, Athéna avec la branche d'olivier et une Niké (une Victoire) auprès d'elle.

${ }^{24}$ Pausanias I, 26,5, commenté récemment par Pirenne-Delforge (2010, p. 147-163) ; Euripide est l'auteur d’une tragédie Erechthée dont des fragments sont conservés et que l'on a été tenté de mettre en rapport avec la construction de l'Erechtheion dans les vingt dernières années du Ve siècle (Jouan e Van Loy, 2000); à propos de Poséidon à Athènes, après la victoire d’Athéna, voir aussi plus bas note 33.
} 
Sur notre vase, du troisième quart du VIe siècle, les deux divinités sont représentées dans un face à face paisible, solennel, sans aucun élément évoquant la querelle. Ils échangent un geste de salutation. Cette représentation n'est pas totalement isolée. D'abord, comme un précurseur de la scène de l'amphore de Paris, il faut citer la scène surprenante représentée sur un plat votif thasien à figures noires, daté du deuxième quart du VIe siècle. Il provient de l'Artémision de Thasos et constitue le vase éponyme du Peintre de Poséidon et d'Athéna. La composition réunit trois figures. Au centre, on reconnaît Poséidon à son trident. Face à lui, se trouve le plus probablement Athéna, même si elle ne porte ni casque, ni égide, ni lance ou bouclier. L'identité du troisième personnage, à gauche, est plus problématique. Il est de taille bien inférieure aux deux autres et porte, sur une tunique courte, une peau de bête attachée. On a proposé d'y reconnaître Hermès ou encore Héraklès. (fig. 3$)^{25}$. Y a t'il dans cette composition une allusion à l'épisode de la dispute pour la possession de l'Attique, peu aisée à justifier à une date si ancienne et dans le contexte thasien?

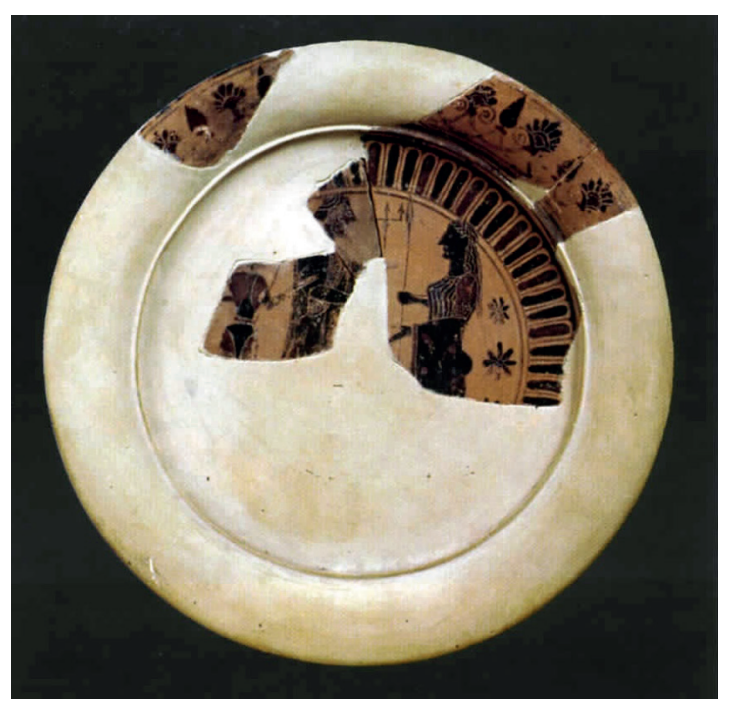

Figura 3

Regardons cette fois dans le contexte athénien et plus précisément encore, dans celui de l'Acropole. Deux fragments d'un kotyle-cratère, attribué à Sophilos, y ont été trouvés ${ }^{26}$. Sur l'un des deux, le nom de Poséidon est écrit le long d'une tête de cheval et, devant celle-ci, une figure masculine barbue se trouve à côté d'une figure féminine. Il serait possible d'identifier ces deux figures comme le couple de Poséidon et Amphitrite, mais l'inscription peut correspondre, aussi, à une figure, aujourd'hui disparue, près du cheval.

${ }^{25}$ Coulié (2002, p. 54-55 et pl. II).

${ }^{26}$ Acr. 585 A et B : ABV 40,17 et 18; BA 28625: Bakir (1981, p. 68 A17, p. 26-27, fig. 17-18, pl. 36) ; Baurain-Rebillard (1999, p. 159) ; Sourvinou-Inwood (2008, p. 128-131) ; Elisabetta (2012, p. 112-113 et fig. 52) 
Sur le deuxième fragment, se trouvent deux figures féminines qui partagent le même manteau. L'une est désignée par une inscription comme Pandrosos, l'autre pourrait être une de ses deux sœurs, plutôt Aglaure. ${ }^{27}$. L'homme barbu, qui se trouve à leur droite, serait Kékrops, leur père. Ce vase, dédié sur l'Acropole un peu avant 580, montrerait Poséidon avec Pandrosos et, peut-être, Kékrops, dans une scène appartenant au plus ancien passé d'Athènes. Si l'on admet l'interprétation récemment proposée ${ }^{28}$, les deux groupes mêlant divinités et mortels, et la présence de Kékrops -qui apparaît parfois comme juge dans le conflit - permettraient d'identifier une scène en rapport avec l'affrontement. Dans ce cas, le mythe ne correspondrait plus à une invention des années 470, mais remonterait beaucoup plus haut dans le temps. Le schéma de la composition d'ensemble nous échappe, mais les parties conservées restituent les circonstances et certains participants de la lutte.

D'ailleurs, un autre vase fragmentaire, provenant aussi de l'Acropole, pourrait présenter une scène en rapport aussi avec l'épisode de la compétition entre les deux divinités qui s'y est déroulée. Il s'agit d'une amphore pseudo-panathénaïque datée vers 540 et attribuée au Peintre de Princeton (fig.4ab) ${ }^{29}$. A la figure d'Athéna en armes dans une position d'attaque entre deux colonnes surmontées d'un coq, ne correspond pas, sur l'autre face une scène athlétique comme le veut la tradition, mais une réunion de divinités. On y retrouve Athéna représentée entre Poséidon, qui se trouve derrière elle, reconnaissable à son trident, et Zeus devant elle, qui lui fait face en tenant le foudre. Deux études ${ }^{30}$ mettent en évidence les éléments de cette scène qui la rattachent au célèbre conflit : les trois protagonistes, Athéna et Poséidon ainsi que Zeus en arbitre, qui prend parti en faveur de sa fille, représentée face à lui. Même si toute analyse d'une représentation si fragmentaire ne peut être que d'une extrême prudence, l'allusion à la rivalité semble très probable. En tout cas, sur le fragment conservé, Athéna et Poséidon sont l'un derrière l'autre et l'affrontement à proprement parler n'est pas figuré. La scène se situe avant ou après le moment critique. Athéna, suivie de Poséidon, est face à son père, le roi des dieux, et sa victoire, imminente ou à peine obtenue, est assuré $\mathrm{e}^{31}$.

\footnotetext{
${ }^{27}$ Comme Pandrosos, Aglauros a sa place dans le contexte religieux athénien: Pausanias mentionne son 'enceinte sacrée' (I 28,2), tandis que la troisième sœur, Hersé, plus effacée, une sorte de doublet de Pandrosos; pour un rôle es filles de Kékrops dans le vote qui donne la victoire à Athéna selon une source tardive (Aelius Aristide) qui pourrait transmettre une version ancienne, voir Elisabetta (2012, p. 115 note 180).

${ }^{28}$ Voir les références citées à la note 27.

${ }^{29}$ Acr. 923 : Marx (2011, p. 21-27); Elisabetta (2012, p. 115); Moore (2013, p. 26-36).

30 Voir Marx et Moore (supra note 31).

${ }^{3}$ Une lékanis fragmentaire à figures rouges (Acr 594) datée vers 400, est mentionnée par Elisabetta (2012, p. 111 et fig. 49,50,51), comme unique autre exemple assuré de la lutte, en provenance de l'Acropole.
} 


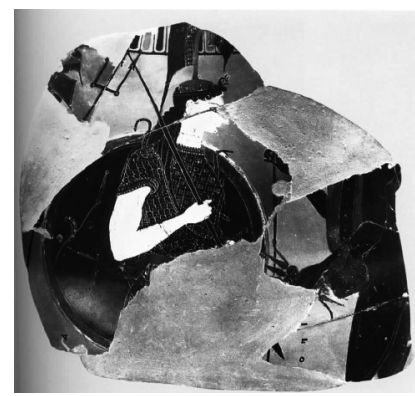

Figura $4 \mathrm{~A}$

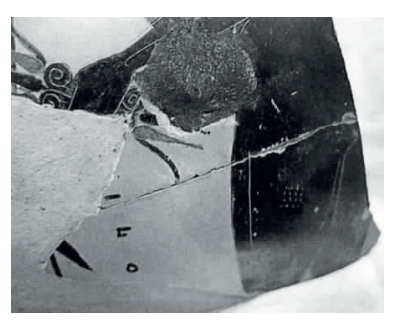

Figura 4 B

A partir de ces deux vases fragmentaires, il vaudrait la peine de reconsidérer le plat thasien, œuvre d'un artisan ouvert à l'influence d'Athènes ${ }^{32}$. En dépit de la présence d'un troisième personnage, l'image qui réunit en un face à face paisible les deux divinités peut-elle être associée au thème de la rivalité qui les a opposés ? En tout cas, ces deux vases fragmentaires établissent, très vraisemblablement, l'existence ancienne de l'épisode mythique. La nouveauté dans la scène du fronton du Parthénon, reprise dans les images qui en dérivent, résiderait dans le moment choisi : l'instant où tout bascule, et l'audacieuse composition pour le rendre.

La composition du Peintre d'Amasis contraste fortement avec celles du rendu d'une très âpre compétition entre les deux divinités pour la suprématie sur Athènes et l'Attique. Aucune violence n'est sous-jacente dans la figuration de ce face à face divin, à la fois paisible et solennel. Doit-on comprendre qu'après la victoire d'Athéna, qui semble bien appartenir au fond ancien des mythes liées à l'Acropole, les relations entre les deux divinités se sont apaisées et que chacun a trouvé sa place sur le rocher qui domine la Cité ${ }^{33}$ ? D'ailleurs, comment imaginer, dans une cité, et à plus forte raison à Athènes, l'effacement d'une divinité comme Poséidon "l'ébranleur du sol" dont les pouvoirs s'étendent sur la mer mais aussi sur tous les mouvements venus des profondeurs de la terre : séismes et catastrophes naturelles, et qui est, de plus, lié au cheval ? En tout cas, chez les peintres attiques de l'époque archaïque, cette représentation reste unique. Poséidon et Athéna peuvent assister ensemble à

32Voir (Coulié, 2002, p. 43-44).

${ }^{33}$ A propos de Poséidon le "loser", voir en particulier, Parker (1987, p. 199) ; sur la place de Poséidon à Athènes après la victoire de la déesse, Darthou (2008, p. 269-285). 
des événements importants de la vie des Olympiens, comme la naissance miraculeuse de la déesse, où Poséidon, reconnaissable à son trident, est présent sur les plus anciens témoignages conservé ${ }^{34}$, ou encore la Gigantomachie, la lutte des dieux contre les géants, dans laquelle Athéna joue un rôle prééminent ${ }^{35}$. Poséidon peut aussi être présent parmi les divinités qui accueillent Héraklès, conduit par Athéna, dans l'Olympe ${ }^{36}$. Mais leur participation à un même événement n'implique pas de rapprochement particulier entre eux, tel celui figuré sur l'amphore de Paris. Le seul parallèle à cette scène se trouve sur un vase, à la fois beaucoup plus tardif et unique, une amphore panathénaïque en miniature et à figures rouges, datée vers $400^{37}$, où l'on voit Poséidon debout, la jambe gauche levée et le pied appuyé sur un rocher, et tenant de sa main droite son trident face à Athéna armée. Sur l'autre face du vase, Hermès est représenté entre deux oliviers. Ainsi, la rivalité est évoquée en même temps que le face à face apaisé, et les deux temps comme liés.

\section{La composition du Peintre d'Amasis contraste fortement avec celles du rendu d'une très âpre compétition entre les deux divinités pour la suprématie sur Athènes et l'Attique}

De plus, en regardant du côté du corpus du Peintre d'Amasis, on peut noter une très importante présence de Poséidon, qui n'a pas d'égal chez les autres peintres de vases de son temps. En premier lieu, il faut mentionner un regroupement très proche d'Athéna et de Poséidon sur une autre amphore signée du potier Amasis et attribuée au Peintre.d'Amasis ${ }^{38}$. La face A où se tiennent, l'un face à l'autre, Athéna et Poséidon, n'est pas intacte, mais l'identité des deux figures incomplètes ne laisse pas de doute. La même réunion se retrouve sur une oenochoé conservée à Florence ${ }^{39}$ où les deux divinités n'apparaissent pas seules mais entourées de deux autres figures masculines, accompagnées chacune d'un chien. L'une se laisse aisément reconnaitre comme Hermès. Une scène représentée sur une olpé conservée au musée du Louvre ${ }^{40}$ est plus complexe.

\footnotetext{
${ }^{34}$ Par exemple sur l'exaleiptron attique à f.n. attribué au Peintre C au Louvre CA 616, vers 570-560: ABV 58,112; BA 300499; Denoyelle (1994, p. 66-67, n. 28).

${ }^{35}$ Par exemple sur une amphore attribuée au Peintre du Vatican 365, Munich SH 1437, vers 540 : BA 745 ; CVA 7. pl. 339-340

${ }^{36}$ Par exemple sur le cratère en calice d'Exékias, Athènes, Musée de l'Agora AP 1044 : ABV 145,19; BA 3104 01; Mackay (2010, pl. 81) : Poséidon est dans le cortège qui accompagne Héraklès; en route vers l'Olympe; sur l'amphore d'Exékias à Orvieto, collection Faina 2748: ABV 144,9; BA 310391 ; Mackay (pl. 40-41) : il figure parmi les Olympiens parmi lesquels le héros a pris place.

${ }^{37}$ Baltimore, Walters Art Gallery 48.59: Godess and polis the panathenaic festival in ancient Athens, cat. exposition sous la direction de Jennifer Neils, The Trustees of Darmouth College, Hanover (New Hampshire) et Princeton University Press, Princeton (New Jersey), p. 45 et 189, n. 66 ; la représentation est rapprochée du groupe sculpté d'Athéna faisant surgir l'olivier et Poséidon la vague mentionné par Pausanias sur l'Acropole $(\mathrm{I}, 25,3)$.

${ }^{38}$ Boston 01.80. 26 où d'ailleurs Dionysos figure aussi, à deux reprises, sous chaque anse, muni de grands rameaux de vigne et de lierre: ABV152,26 et 687; BA 310453; Von Bothmer (1985, p. 130-133, n. 24).

${ }^{39}$ Florence, Musée archéologique 379: ABV BA. Esposito et Tommaso (1993, p. 32, fig. 31).

${ }^{40}$ Louvre F 30 : ABV 152,29 et 687; BA 310456; Von Bothmer (1985, p. 140-142, n. 27).
} 
Il s'agit de l'épisode bien connu de l'introduction d'Héraklès dans l'Olympe. Hermès et Athéna guident le héros comme il est d'usage. En revanche, ce n'est pas Zeus, mais Poséidon qui accueille le cortège. On connaît seulement un autre exemple qui pourrait représenter le dieu des mers dans cette fonction ${ }^{41}$. Faut-il attribuer à cette présence insolite une signification forte comme le proposait Pottier ${ }^{42}$ qui évoque la présentation du héros à Poséidon en tant que propriétaire ancien de l'Acropole par sa protectrice Athéna et l'introducteur ordinaire des ambassades divines, Hermès? La question reste ouverte mais elle indique une situation extraordinaire à propos de Poséidon que confirment encore d'autres œuvres de notre peintre, au contexte plus difficile à élucider. Sur une olpé fragmentaire conservée à $\mathrm{Oxford}^{43}$, le contexte de la scène qui réunit cinq figures nous échappe. Mais au centre, Poséidon tenant son trident et Athéna, casquée, tenant sa lance et son bouclier, dont l'épisème consiste en un foudre impressionnant, sont face à face. Deux éléments caractéristiques du corpus de notre peintre se trouvent réunis sur cette scène: une place spéciale faite à Poséidon, en particulier avec Athéna, et un goût pour des scènes qui réunissent figures divines et personnages sans aucun attribut et au statut indéterminé, peut-être simplement humains dans une occasion pour nous obs$\operatorname{cure}^{44}$. Les deux faces d'une amphore conservée à Copenhague ${ }^{45}$ présentent également ce type de réunion où figurent, côte à côte, des figures divines identifiables et des personnages à l'identité incertaine, dans un contexte qui nous échappe. S'y trouvent encore Poséidon et Athéna, mais cette fois chacun sur une face différente. Il en est de même sur le revers d'une amphore du Musée $\mathrm{du}$ Louvre $^{46}$, qui réunit trois personnages : à droite, Poséidon est clairement identifiable à son trident, devant lui, le personnage masculin armé et casqué qui tient un chien attaché à une laisse à gros anneaux, reste pour nous anonyme (on a proposé qu'il puisse s'agir d'Arès). A droite, une figure féminine pourrait être Athéna, ou encore Aphrodite. La réunion des deux divinités est ici incertaine, la présence de Poséidon, elle, assurée. Enfin, une coupe attribuée à notre peintre ${ }^{47}$ représente Poséidon dans un épisode homérique dont on ne connaît pas d'autre exemple figuré. Au début du chant 13 de l'Iliade ${ }^{48}$, Poséidon quitte son palais d'or sous les mers pour aller encourager les Grecs à reprendre le combat contre les Troyens. Sur la face A de la vasque de la coupe, sont représentées les écuries du souverain des mers : des colonnes supportant un entablement de métopes et de triglyphes indiquent le lieu de la scène où

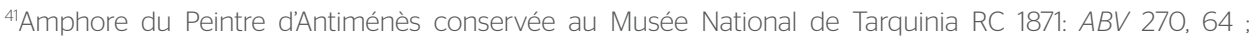
BA 320074 : la scène réunit Héraklès entouré d 'Hermès et de Poséidon.

${ }^{42}$ Pottier (1889, p. 31-37) : l'auteur situe la scène dans un contexte de "conciliation" entre le culte ionien personnifié par Poséidon et Athéna et le culte dorien représenté par Héraklès, sans doute dépassée; il rapproche néanmoins l'olpé de l'amphore du Cabinet des Médailles, témoins toutes deux des préoccupations religieuses du moment.

${ }^{43}$ Oxford 1929.19: ABV BA; Von Bothmer (1985, p. 145-146, n. 29).

${ }^{44}$ Caractère noté par Boardman (1987, p. 147).

${ }^{45}$ Copenhague Musée National 14347: Paralipomena 65 ; BA 350466 ; Von Bothmer (1985, p. 99-101, n. 13).

${ }^{46}$ Louvre F 25 : ABV 150,4 et 687 ; BA 310431; Von Bothmer (1985, p. 97-98, n. 12).

${ }^{47} \mathrm{New}$ York, MMA 1989.281.62 (ex-collection N. Schimmel, Kings Point (NY) Attribution Herbert

Hoffman :Paralipomena 67; BA 350483; Von Bothmer (1985, p. 217-220, n. 60).

48/liade 13, 10-58.
} 
des figures masculines de différentes tailles s'affairent autour des chevaux. Sur la face $B$, le dieu au trident en personne- alors que dans le récit homérique, il prend, pour la circonstance, l'apparence du devin Calchas- encourage deux hoplites dans lesquels on reconnaît les deux Ajax.

Cette rapide enquête à l'intérieur du corpus iconographique du Peintre d'Amasis met en évidence l'importance qu'a, dans ses choix et/ou de ceux qui les orientent, le dieu Poséidon. Il y est largement plus présent que dans les autres œuvres de la même époque ${ }^{49}$. On note encore une tendance particulière à représenter le dieu face à Athéna, en un paisible tête à tête dans lequel ils sont seuls ou encore entourés d'autres figures. Le dieu intervient aussi dans des contextes où on ne l'attendrait pas, comme l'introduction d'Héraklès dans l'Olympe. Enfin, on ne connaît pas de parallèle figuré à la scène homérique dont il est le protagoniste.

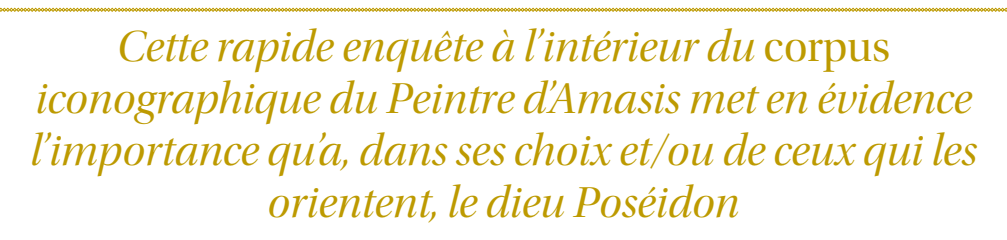

Regardons l'autre face de l'amphore de Paris où Dionysos reçoit l'hommage de deux ménades. La présence des scènes dionysiaques est très importante dans l'œuvre du Peintre d'Amasis. Le dieu est même celui qui apparaît le plus souvent dans ce corpus $^{50}$, comme d'ailleurs c'est le cas dans l'ensemble de la production du Céramique à la fin de l'archaïsme. Cependant, outre la place très importante que lui accorde le Peintre d'Amasis, c'est surtout, sa manière de représenter l'univers dionysiaque qui se révèle originale. Sur le vase du Cabinet des Médailles, la figure du dieu lui-même est traditionnelle. En revanche, les deux figures féminines qui s'avancent vers lui en dansant et en lui apportant les produits de leur chasse sont plus étonnantes. Certes, la danse animée est une des caractéristiques de ce type de personnage. Certains attributs permettent aussi de l'identifier : ils constituent ce que l'on pourrait appeler la "livrée" dionysiaque, l'ensemble d'objets qui marquent l'appartenance au dieu et qui caractérisent ce type iconographique. Sur notre vase, elles portent la couronne et le rameau de lierre, la plante toujours verte, familière de l'image du dieu lui-même, fortement lié à la nature et dont le pouvoir ne connaît pas de limite temporelle. L'une d'elles porte aussi la pardalide, la peau de panthère nouée sur son péplos, je reviendrai sur cet élément.

\footnotetext{
49Un rapide sondage dans l'œuvre d'Exékias, autre personnalité importante du Céramique au même moment montre que Poséidon y apparaît exclusivement dans des assemblées divines : celles qui accueillent Héraklès dans l'Olympe : amphores d'Orvieto, collection Faina 2748 et 2745: ABV 144,9; 145,11 et 686 ; BA 310391 et 310393; : Mackay (2010, pl. 41 et 47); cratère en calice, Athènes, Agora AP 1044 : ABV 145,19 et 672,4; BA 310401; Mackay (2010, pl. 81).

50Pour un essai de statistiques voir Puig (1999, p. 169-180 ; 2009, chap. V A, p. 109-122).
} 
On peut dater la constitution du type iconographique de la ménade autour du milieu du VIe siècle, un peu avant sans doute, dans l'œuvre du Peintre Lydos et de certains peintres d'amphores tyrrhéniennes, puis du Peintre d'Amasis ${ }^{51}$. Attitude, gestuelle et surtout attributs commencent à la différencier nettement ${ }^{52}$. Cependant, Lydos représente volontiers la figure dans un contexte narratif, comme le retour d'Héphaïstos dans l'Olympe, escorté de Dionysos et de son cortège de ménades et de satyres ${ }^{53}$, alors que notre peintre représente des scènes d'hommage au dieu qui ne sont pas liées à un événement particulier. Notons enfin qu'un des domaines dionysiaques par excellence, celui du vin, n'est connoté sur la scène de l'amphore du Cabinet des Médailles que par le canthare tenu par le dieu. Les deux ménades, n'ont aucun contact avec le breuvage divin. On a parfois voulu réserver ce mode d'accès au dieu au monde masculin et plusieurs scènes représentées par notre peintre présentent des jeunes gens faisant au dieu l'hommage du vin ${ }^{54}$. Pourtant, il a aussi représenté des ménades un canthare ou une oenochoé à la main, autour du dieu ${ }^{55}$ ou encore enlacées à un satyre ${ }^{56}$. Notre peintre connaît aussi cet aspect subversif comme une des composantes de la figure féminine dans le cercle dionysiaque. J'interprèterais dans le contexte précis du thème iconographique en formation la variété des figures dionysiaques féminines chez lui. En effet, autour de Dionysos et dans la même scène que des ménades vêtues et portant des attributs ou dans des scènes séparées, il représente des figures féminines nues, alors que dans l'imagerie archaïque, seules les hétaïres (les prostituées), sont représentées nues. Sur une amphore perdue de Berlin ${ }^{57}$ (fig.5), Dionysos occupe le centre de la composition, entouré de deux couples formés d'une ménade nue, le bras passé autour de l'épaule d'un satyre ithyphallique, puis de deux ménades habillées et couronnées de lierre. Celles que je qualifierais de ménades nues ${ }^{58}$ empruntent à l'hétaïre son schéma iconographique. Ce qui rend possible cette image est une composante du personnage ménadique, présente dès la constitution de la figure et qui l'accompagne tout au long de son histoire, avec parfois de fortes résurgences et qui en fait une femme hors normes ${ }^{59}$. Loin d'être recluse dans l'espace du gynécée et

\footnotetext{
51'ai tenté de tracer les débuts du type iconographique (2009, chap. IV, p. 79-108).

${ }^{52}$ Edwards (1960, p. 78-87), dresse le portrait de la ménade caractérisée par des attributs constitutifs du type iconographique, repris et discuté par Heinrichs (1987, p. 100-102).

${ }^{53}$ Cratère à colonnettes New York MMA 31. 11.11, vers 550 : ABV 108, 5; Paralipomena 43 ; BA 310151 ; Puig (Op. cit., fig. 19-20)

54Par exemple sur la face A de l'amphore de Munich 8763 (Paralipomena 65 ; BA 310434; Von Bothmer, 1985, p. 79-80, n. 4) Dionysos debout devant une grande amphore posée au sol tend son canthare à un jeune homme qui le remplit à l'aide d'une oenochoé. Un autre jeune homme porte une outre, tandis que les deux autres s'avancent vers le dieu avec du gibier; pour les scènes de satyres au pressoir voir infra notes 64-65. ${ }^{55}$ Amphore de Bâle Kä 420: Paralipomena 65 ; BA 350468 ; CVA 1, pl. 29.

${ }^{56}$ Amphore fragmentaire de Samos, musée de Vathy K 898 : ABV 151,18 et 687 ; BA 310445 ; Beazley (1986 fig. 56, 2).

57Berlin 3210 : ABV 151,21 et 687; BA 310449; Dionysos verwandlung und ekstasie, catalogue d'exposition sous la direction de Renate Schlesier et Agnès Schwazmaier p. 50, n. 8, Staatliche Museen zur Berlin et Schnell \& Steiner, Regensburg, 2008, p. 50, n. 8 ; voir aussi l'amphore fragmentaire de Samos K 898 citée note 56 ; il faut noter un exemple corinthien antérieur sur un lécythe de Berlin 3243 daté vers 560: Dionysos, p. 18 et p. 180-181, n. 31: satyres et femmes nues à la peau blanche sont représentés en symplegma.

${ }^{58}$ Beazley (1986, p. 56 : "naked maenads") ; Von Bothmer (1985, p. 49, fig. 43 : "maenads") en revanche, IslerKérényi (2007, p. 134 : “hétairai"); voir Puig (2012, p. 209-223).

${ }^{59}$ Voir par exemple Neils (2000, p. 203-226).
} 
adonnée aux tâches domestiques et familiales, elle parcourt les espaces sauvages et chasse comme un homme. Comme un homme aussi, elle boit le vin. Aussi, la nudité, loin de représenter une quelconque nudité rituelle, traduit, me semble t-il, ce même aspect du personnage.

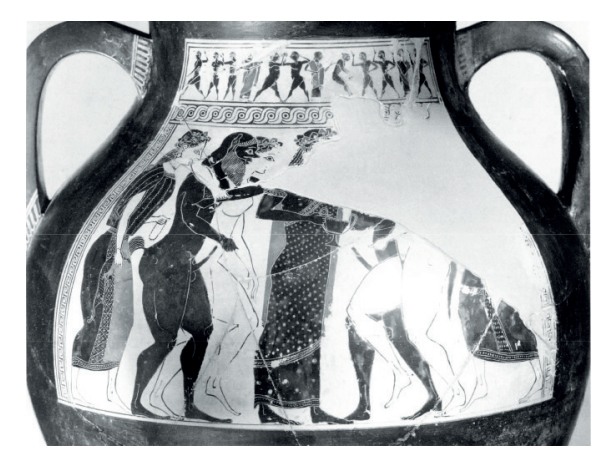

Figura 5

Les ménades de notre amphore sont aussi caractérisées comme chasseresses par le gibier que chacune apporte au dieu. Or, la chasse est une activité typiquement masculine et le thème de jeunes chasseurs faisant hommage au dieu du produit de leur chasse est bien attesté, nous l'avons vu, dans le corpus du peintre. Celui-ci a représenté aussi une autre ménade apportant à Dionysos un lièvre mort ${ }^{60}$. Aussi, ces figures traduisent-elles un aspect transgressif de la ménade, qui pratique une activité masculine : la chasse. Nous avons à faire à une mise en image originale d'un aspect constitutif du personnage dont on trouvera une autre expression, littéraire et beaucoup plus tardive, dans la tragédie d'Euripide Les Bacchantes, créée dans les dernières années du Ve siècle. C'est pourquoi la signification érotique du gibier offert en cadeau à l'aimé et largement attesté et étudié ${ }^{61}$ - on en trouve au moins un exemple chez le Peintre $\mathrm{d}^{\prime} A m a s i s^{62}$ - me semble étrangère à cette représentation.

Les deux ménades de notre amphore sont seules face au dieu, en l'absence de tout élément masculin : satyres qui forment avec elles le thiase traditionnel ou figures masculines plus proches du komos que du thiase ${ }^{63}$. Certes, dans l'univers dionysiaque du peintre, l'un et l'autre existe ${ }^{64}$. Il représente également le dieu dans un entourage strictement masculin: des satyres vendangeurs par

\footnotetext{
60Berlin 3210 voir supra note 57.

${ }^{61}$ Voir en particulier Schnapp (1997); pour le sens du gibier dans le contexte dionysiaque, voir Heinrichs (1987. p. 103-105) : la ménade qui tient un animal est vue comme une descendante de la Maîtresse des animaux. ${ }^{62}$ Coupe skyphos du Louvre A 479: ABV 156,80 et 680; BA 310509; Von Bothmer (1985, p. 200-203, n. 54), où des couples d’amoureux échangent des cadeaux: on y trouve à la fois le lièvre et le cervidé mais offerts dans un contexte homoérotique masculin ; les deux femmes, nues elles aussi comme toutes les figures du vase, ne reçoivent pas de gibier, mais se voient offrir une poule et un bouton de lotus.

${ }^{63}$ Pour la définition précise du thiase, voir Jaccottet (2003, p. 15-29); pour le passage du komos au thiase dans l'entourage de Dionysos, voir Puig (2009, p. 79-84 et 95-97).

${ }^{64}$ Pour Dionysos entouré de satyres et de ménades, voir par exemple la coupe du Louvre F 75 (le dieu est accompagné d'Ariadne): ABV 156,81 et 688; BA 310510; Von Bothmer (1985, p. 210-211, n. 57); ou les frises secondaires de l'amphore de Wurtzbourg L 265: ABV 151,22; BA 310451 ; Von Bothmer (1985, p. 61, n. 19); ménades et figures masculines nues sur l'amphore de Bâle, Antikenmuseum Kä 42O: Paralipomena 65; BA 350468, CVA 1, pl.29 ou l'amphore du Louvre F 36: ABV 150,6 et 687; BA 310433; Von Bothmer (1985, p. 81, n. 5).
} 
exemple, ou au pressoir ${ }^{65}$ et il pourrait être le premier à composer de telles images où la fabrication magique du vin est immédiatement liée à sa consommation et aux effets de celui-ci, ou encore de jeunes chasseurs, totalement humains ${ }^{66}$. L'univers du vin, celui de la chasse sont des territoires masculins qui entrent l'un et l'autre dans le très complexe et riche univers du dieu. Cependant, ces "ménades entre elles", face à leur dieu, offrent une vision forte de la connivence entre les femmes et Dionysos, un élément qui est présent au tout début du thème. Sur une amphore "tyrrhénienne" du Louvre (fig.6) ${ }^{67}$ datée des années 560-550, une des plus anciennes scènes ménadiques, légèrement antérieure à l'amphore du Cabinet des Médailles, Dionysos est assis devant une large vigne et entouré de six ménades, en dehors de toute présence masculine. En dépit du rendu fruste, leur danse agitée est perceptible dans leurs larges enjambées et les mouvements des têtes comme des bras. Deux d'entre elles tiennent des animaux qui figureront parmi les attributs ménadiques traditionnels: un serpent et un jeune fauve, sans doute une panthère. Cela a été noté à de multiples reprises: le contact avec Dionysos est plus aisée pour les femmes que pour les hommes qui, le plus souvent, se font satyres, c'est-à-dire créatures mixtes, mi-hommes mi-bêtes pour approcher le dieu. Les femmes, au contraire, gardent leur totale apparence humaine et pourtant, les deux ménades portent une peau d'animal nouée sur leur vêtement. Leur proximité avec le dieu en fait les intermédiaires privilégiés entre lui et la Cité.

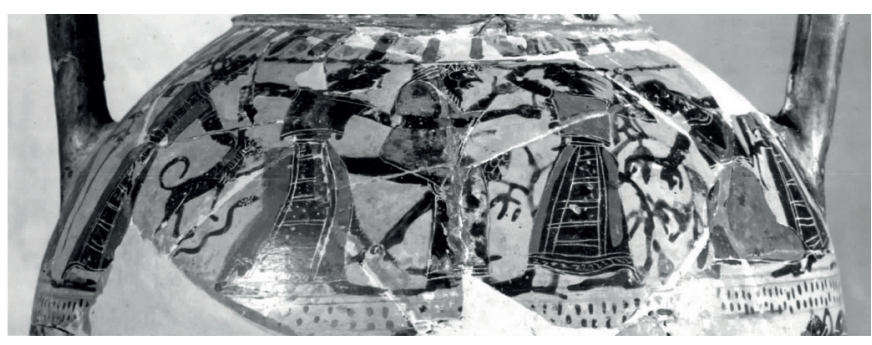

Figura 6

Enfin, la gestuelle des deux figures, qui s'approchent du dieu en dansant et en passant chacune le bras autour du cou de l'autre, a été abondamment et différemment commentée. On a parfois voulu lui donner une signification homoérotique ${ }^{68}$. Or, ce geste précis se retrouve deux fois dans le corpus dionysiaque du Peintre d'Amasis : deux satyres sont ainsi représentés, tandis qu'ils se joignent à une danse autour du dieu, particulièrement animée sous l'effet

\footnotetext{
${ }^{65}$ Amphores de Wurtzbourg L 265 et de Bâle Kä 420 citées note 64.

${ }^{66}$ Sur l'amphore de Munich 8763: Paralipomena 65 ; Von Bothmer (1985, p. 79-80, n. 4), Dionysos est entouré de quatre jeunes gens chasseurs et porteurs de vin; sur l'amphore de Bloomington, Indiana University Art Museum 71. 82: Paralipomena 65; BA 350464; Von Bothmer (1985, p. 63 et 74-75, n. 2), le dieu est entouré de quatre jeunes gens nus, armés de lance et accompagnés de deux chiens.

67Louvre E 831: ABV 103,108; Paralipomena 35,108; BA 310451: l'amphore est attribuée par Kluiver (2003, p. 8081 et 166, n. 211) au Peintre de Guglielmi et datée par lui vers 560-550; Puig (2009, p. 98-99, fig. 18), avec une discussion sur la datation de l'œuvre.

${ }^{68}$ Rabinowitz (2002, p. 128-129); Isler-Kerényi (1990, p. 63 et 2007, p. 134-135).
} 
du vin ${ }^{69}$; un satyre et une ménade avancent aussi, bras dessus bras dessous, vers le pressoir où, sous le regard du dieu, deux satyres s'activent à la préparation du vin ; deux autres tiennent de la même manière deux ménades nues, couronnées de lierre ${ }^{70}$. Aussi, la signification homoérotique du geste ne me semble guère probable. D'ailleurs, pour la défendre, on s'appuie sur une existence attestée de ce type de relation érotique entre ménades, qui vivraient dans leur attachement à Dionysos, une phase de transition entre une étape de vie et une autre, telle celle vécue à Brauron dans la sphère d'Artémis et qui s'exprime pour les fillettes athéniennes par "faire l'ours" pour la déesse ${ }^{71}$.

\section{Les ménades de notre amphore sont aussi caractérisées comme chasseresses par le gibier que chacune apporte au dieu. Or, la chasse est une activité typiquement masculine et le thème de jeunes chasseurs faisant hommage au dieu du produit de leur chasse est bien attesté, nous l'avons vu, dans le corpus du peintre}

Ce rapprochement est-il pertinent? Pour ma part, je soulignerai deux points. D'une part, dans la grande étude qu'il a consacrée à l'homosexualité grecque $^{72}$, Dover a évoqué le silence des textes et des images attiques sur l'homosexualité féminine. De plus, dans les Bacchantes d'Euripide, le roi Penthée accuse les Bacchantes du Cithéron, la montagne de Thèbes, de rendre un culte à Aphrodite et non à Dionysos, et de s'abandonner aux étreintes des hommes (v. 221-225 : le terme utilisé arsen signifie plus précisément mâle). Certes, l'inconduite des femmes sous l'emprise de Dionysos est redoutée des hommes mais aucun texte, aucune image, à ma connaissance, n'implique explicitement une relation homoérotique entre elles. Aussi verrais-je davantage dans cette avancée joyeuse des deux ménades qui dansent, bras dessus bras dessous, sur l'amphore de Paris, une traduction chorégraphique d'une forme de solidarité et de complicité féminines, présentes dans le ménadisme et, elle, documentée par une source littéraire. Il s'agit d'un texte rare qui nous met en présence d'une scène de pratique religieuse vécue. Plutarque ${ }^{73}$ rapporte qu'à Delphes, le grand sanctuaire d'Apollon dans lequel Dionysos a une place importante, lors de la troisième guerre sacrée, au moment où les Phocidiens prennent Amphissa (354/353), des thyiades- c'est le nom des ménades à Delphes ${ }^{74}$-sous l'influence de la mania que Dionysos leur a inspirée, s'égarent de nuit jusqu'à Amphissa

\footnotetext{
${ }^{69}$ Amphore de Wurtzbourg L 265, voir note 65.

${ }^{70}$ Amphore de Berlin 3210, voir note 53.

${ }^{71}$ Rapprochement proposé par Isler-Kérényi (2007, p. 135).

${ }^{72}$ Dover (1989)

73Plutarque, De Mulierum virtute 13, Moralia 249.

${ }^{74}$ Puig (1986, p. 31-51).
} 
où elles s'endorment épuisées. Là, des femmes de la ville, craignant pour elles à cause de la présence de nombreux soldats dans la cité et mues par une sorte de solidarité spontanée, les rejoignent, prennent soin d'elles, les nourrissent et les reconduisent jusqu'aux frontières. Certes, Plutarque écrit bien après l'événement qu'il rapporte, mais il est un excellent connaisseur de Delphes. Cet épisode, intéressant à plus d'un titre, constituerait, selon moi, un témoignage d 'une forme de solidarité entre femmes dans le ménadisme, que traduit à sa manière le Peintre d'Amasis.

Enfin, on a noté dans la mise au point de cette figure iconographique comme dans celle, très visuelle également de la tragédie, la présence d 'éléments cultuels, comme empruntés par le peintre à des célébrations vues et connues de lui comme de ses clients du Céramique ${ }^{75}$. Aussi, l'effort de distinguer, parmi les figures ménadiques, celles qui appartiennent au mythe et celles qui appartiennent à la réalité, ou encore la situation de telle scène du corpus au niveau humain, telle autre dans le mythe ${ }^{76}$ me semble vain. Lors de sa constitution même, la figure iconographique mêle les éléments pour exprimer l'être de la femme en contact avec le dieu, celle qui, par le rituel, devient ménade. Un exemple emprunté à un lécythe à figures noires anonyme, daté des années $510^{77}$ (fig. $7 \mathrm{abc}$ ), un peu après la fin de la carrière de notre peintre, permet de visualiser avec une certaine netteté, parce que le rendu est moins élaboré, le travail de "bricolage" qu'a constitué "l'invention" de la figure ménadique. Le dieu, couronné de lierre, tenant un grand canthare et un rameau de vigne y assiste aux évolutions de trois ménades, seules face au dieu, sans figure masculine comme sur notre amphore. Couronnées de lierre comme le dieu, elles portent, en outre, une peau mouchetée nouée sur leur chiton. L'une brandit un lièvre comme une des deux figures de l'amphore du Peintre d'Amasis. Une autre brandit un serpent, un attribut ménadique présent déjà chez Lydos ${ }^{78}$, mais que notre peintre ne semble pas représenter, et un thyrse, la tige de roseau terminée par un bouquet de lierre qui vient d'apparaître chez les peintres à figures rouges appelés Pionniers, Euphronios, Smikros, Phintias, Euthymidès, vers 520515 , pour devenir l'emblème ménadique par excellence ${ }^{79}$. Leur activité tourne autour de la préparation du vin à boire, en rapport avec le canthare tenu par

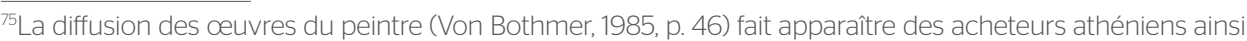
qu'une importante exportation vers l'Etrurie et de nombreuses régions du monde ancien ; je n'entrerai pas ici sur la question de l'influence du goût des clients étrangers; sur ce point, jai réuni un dossier (2015, p. 7-198). ${ }^{76}$ Isler-Kérényi (2007, p. 132 "human level"; p. 134) à propos des figures féminines de l'amphore de Berlin 3210: juxtaposition de deux types féminins "the hetaerae, erotic companions of the satyrs and the nymphs belonging to the world of nature, not connected with male figures", et pourtant un des rares textes littéraires archaïques conservés à propos des silènes n'en fait-il pas "ceux qui s'unissent amoureusement (aux nymphes) au fond des grottes charmantes": Hymne homérique à Aphrodite (v. 262-263).

77 Vienne, Kunsthistorisches Museum 364 (IV 196) : Haspels (1936, p. 53); BA 41017; Puig (2009, p. 195-196 et fig. 43,44,45).

${ }^{78}$ Cratère New York MMA 3111 11: ABV 108,5 et 684 ; BA 310151 ; Puig (2009, p. 104-105 et fig. 19,20).

${ }^{79}$ Par exemple sur le cratère en calice du Louvre G 33 attribué à Euphronios: ARV 14 ; Pasquier et Denoyelle (1990, n. 11).
} 
le dieu. L'une remplit une hydrie, le vase à eau à la fontaine, dont on voit la bouche en gueule de lion, tandis que l'autre vide le contenu de la sienne dans un cratère où s'opère le mélange juste de l'eau et du vin en vue de sa consommation. La scène se déroule sur un fond de rameaux de vigne qui en renforcent le caractère dionysiaque.

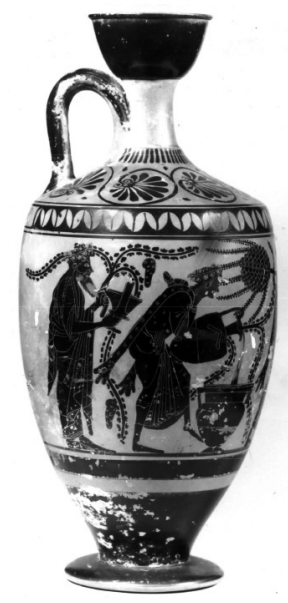

Figura $7 \mathrm{~A}$

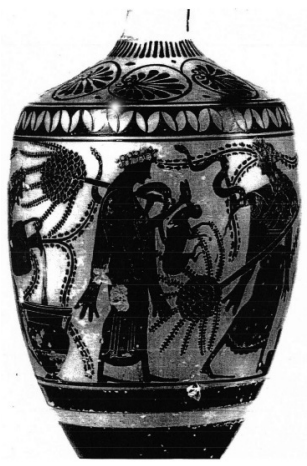

Figura 7 B

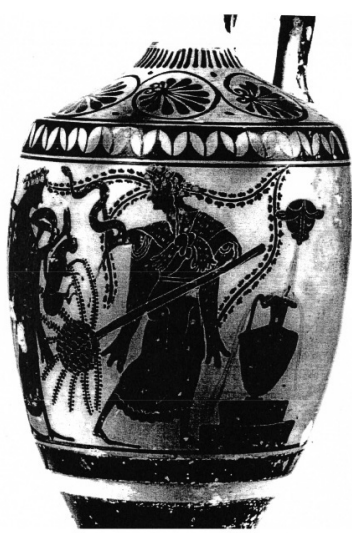

Figura 7 C 
Ma dernière remarque sera pour la manière du Peintre d'Amasis. En effet, les chairs des deux ménades de l'amphore de Paris ne sont pas rendues, comme il est d'usage dans la figure noire, en rehauts blancs, mais au trait de contour, qui laisse apparaître, pour rendre la peau, la couleur orangée de l'argile. Cette particularité se retrouve chez le peintre sur cinq autres vases conservés entiers ou fragmentaires ${ }^{80}$. On y a vu une innovation qui le rapproche de la figure rouge, apparue au Céramique vers 530, durant la dernière période de sa longue carrière. Il se situerait ainsi au seuil de la nouveauté. J. Mertens, dans une étude consacrée à la technique du peintre, à sa manière artistique, ${ }^{81}$ suggère aussi que ces essais, hors de la tradition de la figure noire la plus "orthodoxe", portent, à une exception près, sur des figures de ménade. La seule exception est une figure féminine dans une représentation de départ de guerrier ${ }^{82}$ : la scène n'est pas inscrite mais la somptuosité du bouclier ferait pencher pour une scène héroïque, comme celle d'Achille face à sa mère Thétis. Cette figure féminine est en quelque sorte "une anonyme porteuse de bouclier", une sorte de modèle héroïque. Le peintre sentirait son imagination plus libre et expérimenterait plutôt dans le rendu de telles figures, hors du temps, au statut flottant. L'auteur note en outre que, sur l'amphore de Berlin ${ }^{83}$, les deux ménades nues, entièrement rendues au trait de contour, contrastent fortement avec le corps noir de leur compagnon. A cet effet visuel fort, correspondrait une manière efficace d'accentuer un caractère spécifique de son personnage ménadique, totalement "libéré".

Les figures féminines représentées sur notre amphore montrent donc plusieurs traits originaux. D'abord, la complicité s'y exprime entre l'univers féminin et le dieu. De plus, les ménades du peintre d'Amasis, se situant près, dans le temps, de la mise au point de ce thème iconographique, le peintre y expérimente une grande variété de formules en rapport avec les caractères constitutifs les plus essentiels du personnage. Les ménades de l'amphore de Paris constituent, de ce point de vue, une image frappante d'une forme de bonheur dionysiaque exalté et complice entre deux figures féminines qui s'approchent, dans une danse vive, de la divinité pour lui offrir le gibier, résultat de leur chasse. Celle-ci, qui évoque leurs courses dans la nature sauvage, loin de ce qui est considéré comme l'univers féminin traditionnel.

Originalité dans certains éléments du décor secondaire, dans la manière, sans parallèle connu, de représenter des scènes figurées dont le thème est bien de son temps, que connaissons-nous de ce peintre anonyme qui puisse rendre compte de ces traits qui lui semblent personnels ? Certes, nous savons bien peu des artisans du Céramique qui connaît en cette fin d'archaïsme une forte effervescence créative. Cependant, dans le cas de notre peintre anonyme, un

\footnotetext{
${ }^{80}$ Amphores Berlin 3210 (perdue) et Bâle col. Käppeli 420 voir notes 56 et 55; fragments d'amphore de New York 1985.57 : Von Bothmer (1985, p. 110-112, n.18bis); de Samos et de Kavalla (ibidem p. 109, fig. 67 et p. 116, fig. 76).

${ }^{81}$ Mertens (1987, p. 171-176)

${ }^{82}$ Berlin 3210 (voir supra note 56 ) revers.

${ }^{83}$ Berlin 3210, voir note 57.
} 
nom est néanmoins attaché à des vases qu'il a décorés, celui du potier qui a les a signés: Amasis. Or ce nom, étranger, fournit une piste à ne pas négliger.

Notre amphore a été attribuée par Beazley, ${ }^{84}$ au Peintre d'Amasis, un peintre anonyme qui reçoit son nom du potier Amasis, dont nous avons vu la signature sur l'amphore et dont on connaît plusieurs autres signatures ${ }^{85}$. Des critères stylistiques permettent de noter la très fréquente collaboration des deux artisans, même si l'on ne peut les identifier l'un à l'autre avec certitude. Il est le premier peintre de vases auquel ait été consacrée une exposition monographique, à New York en $1985^{86}$. Elle a rassemblé quelques soixante vases sur les cent trente qui lui étaient alors attribués, répartis durant sa longue carrière que l'on situe entre 560 et 515 . Dans le catalogue de l'exposition, Bothmer signale que, alors que tous les vases signés par le potier Amasis sont attribués au même peintre, le Peintre d'Amasis, et qu'on a donc la tendance à confondre le peintre avec le potier, un lécythe, acheté par le Musée Getty, porte la signature du potier Amasis mais est attribué au Peintre de Taleidès ${ }^{87}$. De plus, la chronologie de la carrière du peintre qu'il propose et qui fait débuter celle-ci vers 560 , rend difficile qu'il ait pu recevoir le nom d'Amasis en lien avec celui du pharaon dont le règne a commencé depuis trop peu de temps ${ }^{88}$. Aucun des vases signés Amasis n'appartient en outre à la première partie de la carrière du peintre. Donc, l'exposition a pour sujet l'anonyme Peintre d'Amasis. La question d'une personne unique continue de traverser la recherche et n'a pas, à ce jour, reçu de conclusion définitive. Notons toutefois l'utilisation faite par Beazley des termes Amasian, Amasea. pour caractériser une manière de peintre et de potier ${ }^{89}$, et sa remarque à propos du Peintre d'Amasis : "A great part of the pleasure one receives from the vases he decorated, whether signed or unsigned, is due to the potter-work, the shape and surface-finish, in fact to Amasis, and the potter Amasis is as clearly defined a personality as the Amasis Painter; he has his own idea of shape, and goes his own way, keeping apart from the majority." ${ }^{90}$.

Arrêtons nous un instant sur le nom Amasis: une forme hellénisée d'un nom égyptien attesté, et en particulier celui d'un pharaon, qui règne de 570 à 526 et se montre philhellène dans une période déjà avancée de son règne. L'historien Hérodote en rapporte plusieurs témoignages ${ }^{91}$. Le nom du potier a été naturellement mis en rapport avec celui du souverain, de plusieurs manières et a induit de nombreuses interrogations sur ses origines. Il peut s'agir d'un Athénien portant le nom d'un souverain étranger ${ }^{92}$. Ce ne serait pas l'unique exemple d'un citoyen d'Athènes ainsi nommé. En effet, l'éphèbe Croissos, qui doit son nom au roi Crésus de Lydie, nous est connu par sa belle statue funéraire réalisée vers

\footnotetext{
${ }^{84} A B V .152,25$

${ }^{85}$ Beazley (ABV, p. 152-158), mentionne 8 signatures sur des vases à figures noires et une sur un vase à figures rouges (repris ARV 160: Ama Group); Von Bothmer (1985, p. 35) mentionne 12 ou 13 signatures.

${ }^{86}$ Pour le catalogue de l'exposition, voir supra note 2 , pour les actes du colloque qui l'a accompagnée, la note 44

${ }^{87}$ Von Bothmer (1985, p. 34 et 229).

${ }^{88} \mathrm{Ce}$ problème fait déjà l'objet d'une exposition claire dans une note par Cook (1948, p. 148); voir ici plus bas.

${ }^{89}$ Beazley (1931, p. 256-285), qui réunit des œuvres du potier comme du peintre.

${ }^{90}$ Beazley (1986, p. 52)

${ }^{91}$ Hérodote II, 178-182.

${ }^{92}$ Voir Karouzou (1956)
} 
$530^{93}$. Mais dans le cas d'Amasis, surgit un problème chronologique malaisé à résoudre : le jeune Athénien ne peut recevoir un tel nom qu'à sa naissance et en rapport avec celui du pharaon et plutôt dans la période où celui-ci témoigne de ses sentiments philhellènes qu'au tout début de son règne. Or, la datation traditionnelle attribuée à l'œuvre du peintre s'accorde mal avec cette exigence. On a également proposé, pour le futur artisan du Céramique d'Athènes, une naissance à l'étranger : il a pu voir le jour en Egypte, et dans ce cas recevoir un nom égyptien bien attesté, sans que celui-ci soit nécessairement lié à celui du pharaon, mais en tant qu'enfant grec, son nom apparaît dans sa transcription grecque $^{94}$. On a suggéré, plus précisément, Naucratis, l'important port commercial du delta du Nil où réside une très importante colonie grecque, comme lieu de naissance. Là, il aurait pu voir les produits des ateliers de Grèce continentale et d'Ionie. Il aurait même pu y connaître les ateliers locaux de Grecs d'Ionie installés sur place et acquérir ainsi, au contact d'une production à la fois variée et d'un haut niveau technique et artistique, une formation qui le suivra à Athènes lorsqu'il s'y installe comme émigré métèque ${ }^{95}$. J. Boardman a proposé, dans une importante étude consacrée à son nom ${ }^{96}$, d'y voir un Grec d'Ionie, un milieu en contact avec l'Egypte, de sorte que le nom du potier ne serait pas insolite et où la production de vases peints présente des caractéristiques propres et nettement marquées de forme et de décor dont il est possible de rechercher des traces dans l'œuvre du potier ou du peintre-potier Amasis. Faut-il rappeler qu'Exékias, son voisin du Céramique, son rival? a peut-être fait allusion à son visage exotique sur une amphore où à côté du compagnon noir du roi Memnon, on peut lire le nom d'Amasis ${ }^{97}$.

Après l'exposition et le colloque de 1985-1987 centrés sur le peintre, c'est davantage vers le potier que se tournent les recherches répondant ainsi au souhait alors exprimé par Boardman ${ }^{98}$. H.P. Isler centre sa recherche sur l'argument chronologique et le rattachement impératif du nom Amasis à celui du pharaon dont le règne est bien daté. Cela le conduit à réviser la datation de la carrière du peintre et à la faire commencer légèrement plus tard, vers 550$545^{99}$. Ainsi, le peintre et le potier peuvent ne faire qu'un ou être, au contraire, deux artisans distincts, la perspective reste ouverte. H. Mommsen, elle, centre son étude sur le potier ${ }^{100}$. Après avoir mis en doute l'authenticité de la signature Amasis sur le lécythe de la Villa Getty ${ }^{101}$, elle s'attache en particulier à dégager les traits qui caractérisent sa manière. Un point touche particulièrement notre propos : sa fine analyse stylistique de l'amphore du Cabinet des Médailles dégage la profonde originalité de sa forme, que certains détails rap-

\footnotetext{
${ }^{93}$ Trouvée à Anavyssos en Attique et conservée au musée national d’Athènes 3851 : Kaltsas (2002, p. 58-59, n. 69).

${ }^{94}$ Boardman (1958, p. 1-3)

${ }^{95}$ Boardman (1958, p. 2).

${ }^{96}$ Boardman (1987, p. 141-152)

${ }^{97}$ Londres, BM B 209 : ABV 148,8 et 686 ; BA 310390 ; Kay (2010, p. 201-213 et pl. 49-51).

${ }^{98}$ Boardman (1987, p. 144).

${ }^{99}$ Isler (1994, p. 95-114).

${ }^{100}$ Mommsen (1997, p. 17-34).

10ivoir supra note 86.
} 
prochent de la Botkin Class mais qui constitue une œuvre originale du potier Amasis. Son analyse du travail du potier la conduit aussi à définir la manière originale dont il assimile des influences pour créer des œuvres profondément personnelles. Nous disposons là de données précieuses concernant la manière propre d'Amasis le potier. De plus, pour l'auteur, l'unité est telle entre ce travail et celui du peintre, qu'elle ne peut s'empêcher de penser à un seul artisan, à la fois potier et peintre. ${ }^{102}$. Sa contribution plus récente ${ }^{103}$ insiste encore sur la profonde cohésion de la forme et du décor et la possible confusion du potier et du peintre. Autrement dit, cette recherche invite à poursuivre dans la même direction concernant cette fois le peintre dans ses choix iconographiques. Sa possible origine exotique influence t'elle les sujets qu'il représente sur les vases et la manière dont il les élabore ? Son style a été analysé presque unanimement comme typiquement attique. On ne perçoit aucun parfum étranger dans les formes ou dans le style selon Bothmer qui a établi la liste de ceux qui l'ont influencé dans l'aire du Céramique d'Athènes, au premier rang desquels son aîné le Peintre de Heidelberg ${ }^{104}$. Cependant, J. Boardman, précisément dans sa contribution consacrée aux implications de son nom, rappelle judicieusement le nombre de peintres de vases, ou encore de sculpteurs nés ou formés ailleurs qui ont contribué à la formation du style attique. Celui de la peinture de vases développée à Athènes est le fruit d'un mélange d'emprunts variés, d'origines diverses ${ }^{105}$. Il poursuit en s'interrogeant, point essentiel à notre enquête présente, sur le choix de ses thèmes, la manière dont il les aborde, son originalité sur ces points, par rapport à ses contemporains comme Exékias et aussi par rapport à la tradition attique majoritaire conduisant de Klitias à Exékias en passant par Lydos ${ }^{106}$.

En conclusion, je voudrais souligner le vif intérêt du programme iconographique de l'amphore du Cabinet des Médailles, remarquable à bien des égards. En effet, les trois divinités qui y sont représentées viennent corroborer ce que nous apprennent d'autres sources à propos de l'univers socio-religieux d'Athènes au temps des Pisistratides. D'autres peintres du Céramique, Exékias par exemple, confirment l'importance de ces divinités. Et pourtant, à y regarder de près, la manière dont le Peintre d'Amasis les représente n'appartient qu'à lui. Le moment choisi, sans contexte narratif, et l'attitude statique des trois divinités représentées sur les deus faces du vase insistent sur leur puissance divine. De plus, l'image du face à face d'Athéna et de Poséidon, à une époque où quelques documents attestent que le thème de leur rivalité pour la possession de l'Attique était le plus probablement connu, se révèle originale dans la mesure où les deux divinités y sont présentées à égalité, comme si, une fois le conflit réglé en faveur d'Athéna, chacune avait trouvé sa place sur l'Acropole.

\footnotetext{
102Mommsen (1997, p. 17-34).

103Mommsen (2009, p. 40).

${ }^{104}$ Von Bothmer (1985, p. 38-42).

${ }^{105}$ Boardman (1987, p. 146) avec renvoi à la contribution d'Alan L. Boegehold dans introduction du catalogue de l'exposition p. 31 ; Viviers (1992) en donne une saisissante image en ce qui concerne.

${ }^{106}$ Boardman (1987, p. 147).
} 
De plus, notre peintre accorde, dans l'ensemble de son œuvre conservée, une importance particulière, qui le distingue parmi les artisans du Céramique au même moment, au dieu des mers et "ébranleur du sol”. Enfin, les ménades qu'il représente face à Dionysos sont exceptionnelles. Il s'agit d'un thème iconographique encore en formation et pour lequel le peintre invente des solutions, à la fois uniques et expressives des plus profondes virtualités de cette figure, promise à un étonnant et très durable succès. Il est tentant d'attribuer ces traits originaux à une possible origine étrangère de l'artisan, même si nous touchons là à la question, sans réponse claire à ce jour, de l'éventuelle identité du potier qui signe Amasis, un nom qui a toutes chances d'indiquer une origine orientale, et du peintre qui a décoré la plupart de ses vases signés. La profonde originalité du potier comme du peintre, tous deux en marge à plusieurs égards par rapport aux autres créateurs de leur temps, donne à une telle assimilation une certaine séduction. Rappelons qu'à l'époque où se termine la carrière de notre peintre, c'est un autre étranger à Athènes, l'anonyme Peintre d'Andokidès qui "invente" la technique à figures rouges. Dans le creuset d'influences d'ailleurs qui constitue alors le Céramique, attribuer une forme d'originalité à un peintre-potier d'origine étrangère constitue une hypothèse qui n'est pas à exclure. Une manière d'entrer dans la difficile problématique de la marge de liberté de l'artisan dans le choix des sujets qu'il aborde et de la manière dont il les représente.

\section{Abbréviations}

$A B V$ : John Davidson Beazley, Attic Black-Figure Vase-Painters, Oxford, Oxford University Press, 1956.

ARV: John Davidson Beazley, AtticRed-Figure Vase-Painters, Oxford, Clarendon Press, $2^{\mathrm{e}}$ éd. ,1963. Paralipomena : John Davidson Beazley, Paralipomena, Oxford, Clarendon Press, $2^{\mathrm{e}}$ éd. 1971. $B A$ : Beazley Archive, Université d' Oxford : www.beazlley.ox.ac.uk.

\section{Table des figures}

Fig. $1 \mathrm{a}-\mathrm{b}$ : Amphore attique à figures noires du Cabinet des Médailles 222, faces A et B : clichés Serge Oboukoff, BnF - CNRS Maison de l'ethnologie et de l'archéologie René Ginouvès, avec l'aimable autorisation du Cabinet des Médailles, BnF.

Fig. 2 a-b: Amphore attique à figures noires du Cabinet des Médailles 222, épaule : d'après Susanne Muth, Gewald im Bild, Berlin. New York, Walter de Gruyter, 2008, p. 160-161, fig. 86 a et b. Fig. 3 Plat thasien à figures noires de l'Artémision 2028 $\pi$ attribuée au Peintre d'Athéna et de Poséidon: d'après Anne Coulié, La céramique thasienne à figures noires, Etudes thasiennes 19, 2002, Athènes, EFA, pl. II nº 140 .

Fig. 4 ab Amphore pseudo-panathénaïque, Musée National d'Athènes, Acr 923, attribuée au Peintre de Princeton, face B, : d'après Patricia A. Marx "Athens NM Acropolis 923 and the Contest between Athena and Poseidon for the Land of Attica” Antike Kunst 54, 2011, pl. 3 fig. 2 et 3.

Fig. 5 Amphore attique à figures noires. Berlin 3210 (perdue) d'après Dionysos Verwandlung und Ekstasi catalogue d'exposition sous la direction de Renate Schlesier et Agnès Schwazmaier p.50, $\mathrm{n}^{\circ} 8$, Staatliche Museen zur Berlin et Schnell \& Steiner, Regensburg, 2008, p. 50, fig. 8.

Fig. 6 Amphore “tyrrhénienne”Louvre E 831 : d'après Marie-Christine Villanueva Puig Ménades. Recherches sur la genèse iconographique du thiase féminin de Dionysos des origines à la fin de la période archaïque, Paris Les Belles Lettres Etudes anciennes, 2009, fig. 18. 
Fig. 7 abc Lécythe attique à figures noires. Vienne, Kunsthistorisches Museum 364 (IV 196) : d'après Marie-Christine Villanueva Puig Ménades. Recherches sur la genèse iconographique du thiase féminin de Dionysos des origines à la fin de la période archä̈que, Paris Les Belles Lettres Etudes anciennes, 2009, fig. 43,44,45.

\section{Références bibliographiques}

BAKIR, Güven. Sophilos. Mayence: Von Zabern, 1981.

BAURAIN-REBILLARD, Laurence. Sophilos, un grand artiste du parlant. In: PUIG, MarieChristine Villanueva et al. Céramique et peinture grecques: modes d'emploi. Paris: École du Louvre/Documentation Française, 1999.

BEAZLEY, John Davison. Journal of hellenic studies, n. 51, 1931.

1986.

. The development of attic black-figure. Edição revista. EUA: University of California Press,

BOARDMAN, John. Amasis: the implications of his name. Papers on the Amasis painter and his world. Anais de colóquio. J. Paul Getty Museum. Malibu, 1987.

. The Amasis Painter. Journal of Hellenic Studies, n. 78, 1958.

BONANSEA, Nicoletta. Menade, baccante o ninfa? Uno studio sull'identità feminile dionisiaca nelle fonti letterarie e iconografiche tra VIII e V secolo a.C. Mythos, n. 2, 2008.

COLONNA, Cécile. Du rouge et du noir: les vases grecs de la collection de Luynes. Gourcuff Graden, 2013.

COOK, R. M. Amasea. Journal of Hellenic Studies, n. 51, 1931.

COULIÉ, Anne. La céramique thasienne à figures noires. Etudes Thasiennes, n. 19, 2002.

DARTHOU, Sonia. Eris dans la cité, quelques réflexions sur les cosmogonies politiques. Mètis, n. $6,2008$.

DENOYELLE, Martine. Chefs-d'œuvre de la céramique grecque. Paris: RMN, 1994.

DOVER, Kenneth James. Greek homosexuality. Cambridge, 1989.

EDWARDS, Mark W. Representations of Maenads on archaic red figure vases. Journal of Hellenic Studies, n. 80, 1960.

ESPOSITO, Anna Maria; TOMMASO, Giandomenico de. Museo archeologico Nazionale di Firenze. Antiquarium vasi attici. Florença: Il Ponte, 1993.

HASPELS, Emilie. Attic black figured lekythoi. Paris, 1936.

HEINRICHS, Albert. Myth vizualized: Dionysos and his circle in the sixth-century attic vase-painting. Papers on the Amasis painter and his world. Anais de colóquio, J. Paul Getty Museum. Malibu, 1987.

ISLER, Hans Peter. Der töpfer Amasis und der Amasis-Maler. 'Bemerkungen zur chronologie und zur person'. Jahrbuch des deutschen archäologischen Instituts, n. 109, 1994.

ISLER-KERÉNYI, Cornelia. Dionysos in archaic Greece. Leyde-Boston: Brill, 2007.

Dionysos in classical Athens: an understanding through images. Leyde: Brill, 2015.

. Identittà maschilli e femminili intorno a Dionysos nell'opera del Pittore di Amasis. Iconografia dionisiaca III. Numismatica e Antichità Classiche, n. 9, 1990.

JACCOTTET, Anne-Françoise. Choisir Dionysos, Akanthu. Kilchberg: Zurique, 2003.

JACKSON, D. A. East Greek influence on attic vases. Londres: Society for the Promotion of Hellenic Studies, 1976.

JOUAN, François; VAN LOY, Herman (Ed.). Euripide VIII, 2. Fragments. Paris: Les Belles Lettres, 2000.

KALTSAS, Nikolaos. Sculptures in the national archaeological museum Athens. Atenas: Kapon, 2002. KAROUZOU, Semni. The Amasis painter. Oxford: Clarendon Press, 1956.

KLUIVER, Jeroen. The "Tyrrhenian” group of black-figure vases. Amsterdã, 2003.

LINDBLOM, Anna. Take a walk on the wild side: the behaviour, attitude and identity of women approched by satyrs on attic red-figure vases from 530 to 400 BC. Stockholm University, 2011. LORAUX, Nicole. Cité grecque. Dictionnaire des mythologies. Direção de Yves Bonnefoi. Paris: Flammarion, 1981. v. I.

MACKAY, E. Anne. Tradition and originality: a study of Exekias. BAR International Series, n. 2.092, 2010. 
MERTENS, Joan R. The amasis painter: artist and tradition. Papers on the Amasis Painter and His World. Anais de colóquio. Malibu: J. Paul Getty Museum, 1987.

MOMMSEN, Heide. AMA I MEПOI EN:Beobachtungngen zum Töpfer Amasis. Athenian potters and painters. Conference Proceedings. American School of Classical studies at Athens, 1994. Edição de John H. Oakley, William D. E. Coulson e Olga Palagia. Oxford: Oxbow Books, 1997.

. Die botkin klasse. In: Shapes and uses of greek vases (7th-4th centuries B.C.). Ed. Athena Tsingarida. Bruxelas: CReA Patrimoine, 2009.

MOORE, Mary B. The Princeton Painter, Athena and Poseidon. Antike Kunst, n. 56, 2013.

NEILS, Jennifer. Others within the other: an intimate look at hetairai and maenads. In: COHEN, Beth (Ed.). Not the classical ideal. Leyde: Brill, 2000.

PALA, Elisabetta. Acropoli di Atene: un microcosmo della produzione e distribuzione della ceramica attica. Roma: L'Erma, 2012.

PARKER, Robert. Athenian religion: a history. Oxford, 1996.

. Myths of early Athens. In: BREMMER, Jan (Ed.). Interpretations of greek mythology.

Oxford: Routledge, 1987.

PASQUIER, Alain; DENOYELLE, Martine (Ed.). Euphronios, peintre à Athènes au VI siècle avant J.-C. Paris: Museu do Louvre/RMN, 1990.

PIRENNE-DELFORGE, Vinciane. Un oikéma appelé Erechtheion (Pausanias, I, 26,5). Paysage et religion en Grèce antique: mélanges offerts à Madeleine Jost. Paris: De Boccard, 2010.

POTTIER, Edmond. Oenochoe du Musée du Louvre signée par le Peintre Amasis. Revue Archéologique, n. 13, 1889.

PUIG, Marie-Christine Villanueva. A propos des thyiades de Delphes. L'association dionysiaque dans les sociétés anciennes. Actes de la table ronde international Ecole française de Rome, 24-25 Mai 1984. Roma: EFA, 1986.

. Deux iconographies dionysiaques parallèles: celle du Pintor d'Amasis et celle d'Exékias. Deux personnalités artistiques? In: PUIG, Marie-Christine Villanueva et al. Céramique et peinture grecques: modes d'emploi. Paris: École du Louvre/Documentation Française, 1999. . Ménades: recherches sur la genèse iconographique du thiase féminin de Dionysos des origines à la fin de la période archaïque. Paris: Les Belles Lettres/Études Anciennes, 2009. . Se dévêtir pour Dionysos? A propos de quelques représentations de ménades nues sur les vases attiques. In: GHERCHANOC, Florence; HUET, Valérie. Vêtements antiques: s'habiller, se déshabiller dans les mondes anciens. Arles: Errance, 2012.

RABINOWITZ, Nancy. Excavating women's homoerotism in ancient Greece: the evidence from attic vase painting. In: RABINOWITZ, N. S.; AUANGER, L. (Ed.). Among women: from the homosocial to the homoerotism in the ancient world. Austin, 2002.

SCHLESIER, Renate; SCHWAZMAIER, Agnès (Dir.). Dionysos verwandlung und ekstasie. Catálogo de exposição. Staatliche Museen zur Berlin e Schnell \& Steiner, Regensburg, 2008.

SCHNAPP, Alain. Le chasseur et la cité: chasse et érotique dans la Grèce ancienne. Paris: Albin Michel, 1997.

SHAPIRO, Harvey Alan. Art and cult under the tyrants in Athens. Mayence: Von Zabern, 1989 (supl. em 1995).

SIMONETTA, Angiolillo. Arte e cultura nell'Atene di Pisistrato e dei Pisistratidi. Bari: Puglia, 1997. SOURVINOU-INWOOD, Christiane. A reading of two fragments of Sophilos. Journal of Hellenic Studies, n. 128, 2008.

STÄHLI, Adrian. Die Vverweigerung der Lüste: Erotische gruppen in der antiken plastic. Berlim: Reimer, 1999.

VIVIERS, Didier. Recherches sur les ateliers de sculpteurs et la cité d'Athènes à l'époque archaïque: Endoios, Philergos, Aristoklès. Bruxelas: Académie Royale de Belgique, 1992.

VON BOTHMER, Dietrich. The Amasis painter and his world. Catálogo de exposição. Nova Iorque, Metropolitan Museum of Art, 1985. 